\title{
Era uma vez em... Hollywood, de Tarantino:
}

\section{A recorrência das imagens}

\section{Tarantino's Once Upon a Time... in Hollywood}

\section{The Recurrence of Images}

João Martins Ladeira

Professor adjunto da UFPR, atuando no Programa de Pós-Graduação em Comunicação e no Departamento de Comunicação. Doutor em Sociologia pelo IUPERJ. Universidade Federal do Paraná, Programa de Pós-graduação em Comunicação, Curitiba (PR), Brasil.

\section{Introdução}

Este texto analisa o filme de Quentin Tarantino Era uma vez em... Hollywood (Once Upon a Time in Hollywood, 2019) na tentativa de abordá-lo através de uma visada teórica que recorra a Benjamin e à sua compreensão imanente dos objetos estéticos. A interpretação ilumina esse objeto recorrendo a problemas contidos na assim chamada Arte Pop (LIPPARD, 1976; MERQUIOR, 2015), construindo uma mediação entre ambos. Não se propõe que a obra pertença a essa escola ou que as especificidades desse trabalho se submetam aos temas de tais artistas. Aqui, busca-se identificar os caminhos pelos quais esforços tão diferentes se constituíram. Nisso, apropria-se da proposta de Benjamin (2009; 2013) inscrita em seu trabalho sobre o Drama Trágico e as Afinidades Eletivas de Goethe. Mais uma vez, não se sugere semelhanças entre tal filme e aquelas obras. Tenta-se retomar o projeto de uma crítica imanente de objetos estéticos, atentando ao conteúdo que se manifesta devido à especificidade de um trabalho. 
Encontra-se em jogo uma discussão sobre o sentido da própria estética numa sociedade industrializada, problema tratado de muitas formas. Contribuição fundadora foram os Estudos Culturais. Inserem-se nessa tradição as tentativas de Williams (1958) de compreender a noção de cultura em construção durante a ação dos intelectuais no âmbito da organização do capitalismo industrial e em momentos-chave da constituição da modernidade. Do mesmo modo, o esforço de apreender a ideologia e a luta por hegemonia esteve em autores como Hall (2003), propondo a abordagem de um texto a partir de forças distintas em conjunção. Foi assim com as manifestações chamadas diaspóricas, que dependem não da imagem de uma origem imaculada, e sim da produção constante, resultado obtido quando se enxerga como se conjugam forças distintas.

Tais contribuições se concentram em mediações sociais, com menor atenção ao objeto estético. Projeto que desperta interesse para a discussão deste artigo consiste no trabalho de Frith (1998) sobre a música pop, investigação voltada a discutir um tipo particular de julgamento, num exercício crítico sobre parâmetros para compreender a cultura capazes de ultrapassar um populismo que apela para a aprovação da maioria como único critério de avaliação para uma expressão. Frith revisa pressupostos retirados das artes, no intento de adequá-los à cultura industrializada. Para ele, o valor da música pop reside em sua dependência da performance. A música gravada lida com a escuta como uma experiência individual, independente da associação coletiva. Mas a performance da música pop reestabelece à atividade um sentido comunal, pautado pela necessidade de manifestar subjetividades. Essa estética expressa a individualidade através de dois traços da música. Um se refere ao corpo. O outro, ao tempo. Esse tempo sempre marcado do pop concede a oportunidade de inscrever no corpo tal performance, transformando essa conexão na chave de tal estética.

Nos termos de Benjamin, tal interpretação permitiu a Frith "salvar" a música pop, retomando um valor de verdade soterrado, impossível de perceber a não ser pelo trabalho da crítica. Na expectativa de aplicar esse projeto estético a Era uma vez, este artigo se divide da seguinte forma. A primeira parte apresenta os termos centrais do debate metodológico de Benjamin, na expectativa de compreender como sua visão sobre a crítica se estabelece. $O$ interesse é se ater às tensões de certos objetos menosprezados, e esse tipo de cinema baseado em restos da televisão e do faroeste parece providencial para tal esforço. A segunda parte apresenta uma interpretação sobre Era uma vez apontando sua conexão com um tipo de 
arte que, em termos compatíveis com o desse filme, recupera a figuração após o esgotamento de certo abstracionismo.

Trata-se de uma tentativa de entender a relação desse cinema específico com a figuração, numa atividade estética que só pode dar conta da abstração muito dificilmente. Por isso, o projeto da Arte Pop de elaborar suas manifestações a partir dos objetos amplamente conhecidos da cultura industrializada permite um esvaziamento e uma retomada desses ícones, transformando-os numa manifestação em que o objeto representado cede importância a outras preocupações. As imagens de Tarantino, construídas através de um repertório de imagens tão conhecidas a ponto de perderem sua qualidade como representações, revelam-se criaturas de direito próprio, reinstituindo nesse cinema a tensão que a Arte Pop descobriu por outros meios. A conclusão do texto encaminha esses problemas numa avaliação sobre o papel da própria cinefilia, na expectativa de se perguntar sobre o sentido dessa atenção às ruínas e restos.

\section{Uma crítica imanente de objetos estéticos: a metodologia de Benjamin}

Embora esta discussão verse sobre o cinema, e Benjamin (2017) se constitua como um autor lapidar para essa técnica, neste artigo suas discussões sobre a reprodutibilidade se mostram menos importantes. Aqui, a atenção se concentra em seu método para compreender objetos estéticos. Motivada por essa proposta, a discussão sobre Tarantino remete ao projeto de Benjamin em sentido mais amplo. 0 problema consiste não na necessidade de uma arte pública, relevante devido à sua capacidade de atingir as massas. Importa menos pensar as contradições introduzidas pela mecanização sobre a estética, o que se desdobra em um diagnóstico sobre a redução de importância do valor de culto frente a uma progressiva expansão do valor de exibição; e em um entendimento sobre o esfacelamento da sensação de distância contida na aura de um objeto (MERQUIOR, 1969). Aqui, tais conceitos sobre o cinema se submetem a outro encaminhamento.

Mais importante se torna a proposta de Benjamin em oferecer uma crítica imanente dos objetos, na expectativa de instituir, a partir deles próprios, o material necessário para sua compreensão. Esse método se motiva por uma tentativa de permitir a revelação das qualidades desses objetos, em vez de submetê-los a qualquer tipo de determinação externa. Abandona-se a pergunta sobre a motivação introduzida pela personalidade de seu autor ou sobre as tendências do movimento que estilos e escolas 


\section{ALCEU}

ISSN: $2175-7402$

deveriam impor à história. Ao contrário de uma interpretação que, por exemplo, privilegie a psicologia de um criador ou o desdobramento de certos traços estilísticos impostos de fora para dentro ao item, a constituição de cada obra importa em seus próprios termos.

Essa proposta se contrapõe a qualquer racionalismo abstrato. Por isso, lida-se com a obra como um produto de linguagem. O crítico surge como um tradutor, permitindo que essas características do material se manifestem. Todavia essa atenção à linguagem se afasta de qualquer projeto semiótico. Não se trata de compreender a composição de um signo, mas de entender toda manifestação como um objeto duplo. Pois, para além de suas qualidades concretas, garante-se um vislumbre de uma dimensão que ultrapassa sua posição no mundo em prol de uma iluminação perceptível apenas na existência do objeto, sem que, contudo, para alcançar esse teor de verdade nele presente, se tenha de aniquilar sua particularidade (GAGNEBIN, 1994; ROUANET, 1981).

Essa proposta se encontra visível nas análise de Benjamin sobre o Drama Trágico e no ensaio sobre Goethe (BENJAMIN, 2009; 2013). O primeiro caso é digno de nota. As peças barrocas da contrarreforma um material bem pontual - reaparecem não como indício de decadência em relação ao Renascimento, no fluxo de estilos na dialética da história. De fato, são uma solução específica para se lidar com certo tema: a dissolução do poder, expressa mediante alegorias recorrentes, versando sobre destruição e redenção. Em vez de se perguntar sobre as motivações de seus autores, tais intenções desaparecem em prol da materialidade do objeto. Desaparece também o lugar dessa literatura num suposto desenvolvimento em direção a certo estilo mais complexo ou importante.

Salvar o Drama Trágico significa indicar em que medida suas alegorias para o poder dependem de certa visão. São obras centradas sempre numa estrutura que distingue três dimensões: o Príncipe, o Cortesão e a Corte. Todos se associam por uma visão que versa sobre melancolia a partir de imagens relativas à luta pelo poder. Os personagens se veem na tensão entre duas figuras: a do mártir e a do tirano. Ambos se deparam com a tentativa de produzir um reino de ordem na Terra, sempre frustrado pelo Destino. Mas essa tentativa inviável carece de um sentido transcendente, como aquela presente na Paixão. Como em um mundo do Velho Testamento, essas tramas envolvem morte e destruição, lidando sempre com um projeto no qual os homens vagam pelo mundo na incerteza da salvação. Esse esquema revela o teor de verdade desse objeto, que existe devido às suas qualidades (ROUANET, 1984). 
Essa exposição se refere a um objeto com séculos de idade, produzido em um contexto extinto, mas que, de alguma forma, ainda reluz. Projeto homólogo se traça na próxima seção, procurando numa obra temas que o método de Benjamin melhor permite enxergar. Desse autor, retira-se como ferramenta a busca por correspondências, na tentativa de estabelecer mediações a partir das quais se possa interpretar a cultura (ARENDT, 1968). Nesse esforço, a análise compreende como esse filme mobiliza restos e ruínas. A habilidade de retomar certas imagens lida com uma capacidade de representação inerente ao cinema, permitindo a essa mídia manipular determinados objetos, conduzindo-os ao seu próprio limite, e, ao mesmo tempo, revelando uma qualidade que se encontra também na Arte Pop.

O conceito de ruína ordena o projeto de Benjamin, abordando a cultura como manifestações que escapam de sua destruição, ainda que se transformem em objetos que carecem da forma que tiveram em outro momento. Obras se deslocam no tempo, distanciando-se no instante em que foram produzidas, como os restos de uma civilização antiga. Mas, a despeito dessa distância, mantêm, como ruína, um vislumbre desse instante pregresso. Logo, revelam-se como uma presença semelhante à do fóssil, conservado depois de a criatura abandonar a vida. Entre tais metamorfoses, Benjamin cita os deuses pagãos integrados ao cristianismo quando sua existência pregressa se revela inviável. Por um lado, resguardam-se de sua destruição. Por outro, diferem agora daquilo que foram outrora. Contudo, nessa sua sobrevivência, não podem ser ignorados (BUCK-MORSS, 2001; WOLIN, 1994).

O trabalho do crítico consiste em buscar nessa ruína a recordação contida em um passado soterrado. Isso transforma a leitura numa lembrança - ou, em outros termos, numa tradução. Nisso, a reflexão sobre a produção industrializada de cultura pode revelar oportunidades ímpares para esse trabalho. Pois ela lidou sempre com termos que regressam, assegurando sua existência ao mesmo tempo que diferem da imagem pregressa. Isso se revela ainda mais radical num instante em que a recorrência dessas imagens adquire tamanha intensidade, como no momento em que emerge o cinema sobre o qual aqui se trata, quando realizadores como Tarantino buscam alternativas em estilizações extremas; ou no momento das artes plásticas em que experiências como as da Arte Pop buscam meios para lidar com o repertório exaustivo da cultura de massa. 


\section{ALCEU}

ISSN: $2175-7402$

\section{Tarantino: uma interpretação}

À primeira vista, Era uma vez em... Hollywood parece ocupar um lugar dúbio no trabalho de Tarantino. Há as infinitas citações a detalhes praticamente imperceptíveis do cinema, que o leigo dificilmente consegue enxergar a olho nu. Nisso, nosso diretor parece agora ainda mais obsessivo do que havia sido até então. Tarantino foi aclamado - como se seus méritos estivessem apenas nisso - pela paródia, pelo emaranhado de referências cruzadas. Seu charme estaria em coletar detalhes, mas essa era uma percepção muito torta de seu trabalho. Decerto, caso seus méritos estivessem apenas em colecionar miudezas, talvez o filme de agora se revelasse seu momento mais alto. Visto assim, não seria nada além de uma visita a um museu, um passeio pelo labirinto da indústria cultural.

Outro traço recorrente do diretor esteve em seu uso da violência; essa que, agora, se mostra estranhamente comedida. Parece faltar ação a este trabalho mais recente. Claro, há a cena final de Era uma vez, com suas bestas ferozes e armas secretas. Mas, durante boa parte do tempo, somos apresentados a um drama interno, pessoal, que talvez só tenha sido tentado em Jackie Brown (1997). De tão pacato, esse novo filme poderia até mesmo chocar um expectador usual de Tarantino. Teríamos, então, um trabalho que, numa direção, exagera aquilo que se costuma esperar desse criador, enquanto, em outro sentido, nega parte do que sua obra costuma oferecer.

A obsessão de Tarantino por citações teria alcançado o máximo, e seu ímpeto pela violência, o mínimo? Teria o diretor finalmente se dobrado às suas próprias excentricidades, imitando a si mesmo como tantos outros já o imitaram? Estaria ele ficando velho? Não se trata disso. Era uma vez indica um ponto bastante maduro em seus esforços e talvez consista num de seus melhores filmes. Nele, várias de suas tendências anteriores se encontram plenamente desenvolvidas. Exatamente a relação com esses dois traços revela que a obra de tal artista se sustenta muito menos por uma ou duas curiosidades, e mais pelo modo como lida com suas imagens, estruturando-as num sistema bastante próprio.

Numa entrevista com Michel Ciment e Hubert Niogret (2013) publicada numa Positif de 1994, ambos conversavam sobre aquela que talvez tenha sido a interpretação mais perspicaz sobre um conjunto de filmes naquela ocasião ainda em franca gestação. Os críticos franceses sugeriram que o trabalho de Tarantino mais parecia um tipo de Arte Pop. Fazia sentido. Neles, existiu sempre uma correspondência falsa com a representação, pois o que vemos nessa obra consiste menos na probabilidade de se enxergar 
qualquer correlação com a verossimilhança, e mais numa fantasia que demanda a reinvenção das imagens e a recuperação de um repertório já conhecido.

A obra de Tarantino tira sua força de uma imensa quantidade de distorção estilizada. Seus filmes expropriam formas cinematográficas passadas - isso todos sabemos. Todavia, importa entender como se obtém, delas, imagens em estado puro. Ninguém duvidou que o modo como seus personagens andavam, falavam e matavam nunca teve nada de real. Na mais concreta das artes, o amor do diretor por tais formas sempre lutou por destruir qualquer concretude. De fato, esse criador sempre foi um Godard da Califórnia, pois em seus filmes o sangue apareceu em todo o tempo apenas como um vermelho. Contudo, a impossibilidade de, em tal trabalho, enxergar-se apenas imagens encontrou reações que dispersavam a energia contida em tais criações.

Tarantino, um "pós-moderno"? Talvez, mas a questão não se esgota em rótulos. Se o diretor pareceu tão interessado em despir seus gângsteres, vaqueiros e ladrões de sua concretude, foi para que em seu lugar surgissem ícones novos, dignos de uma arte puramente abstrata. Mas o cinema não pode se dar ao luxo dessa abstração, pois como poderia se livrar do próprio mundo? Em outra entrevista, uma de 1992 com Peter Brunette (2013), Tarantino explicava o quanto Ihe impressionava o deslocamento realizado por um cineasta como Jean-Pierre Melville em relação aos homens com chapéus e pistolas transplantados do cinema norte-americano. Pois, se soavam absurdos falando em francês e caminhando por Paris, essa justaposição de duas imagens tão díspares oferecia-Ihes um caráter único.

As criaturas de Melville, como as de Tarantino, existem apenas como objetos sem qualquer pretensão figurativa. Após se cansar do real, um pintor pode inventar novas imagens, postura que permitiu às vanguardas redescobri-las. Quando essa abstração se enfraqueceu após um Expressionismo Abstrato exausto de si mesmo, um desdobramento de tais tendências esteve em recuperar a figuração, sem, contudo, o peso que um dia Ihe foi tão caro. Como Merquior (1969) indicou, a Arte Pop se localizava nessa tensão, e nenhuma aposta parecia mais ousada que arrancar essas novas imagens da própria indústria cultural. Se Tarantino não foi o primeiro a descobrir como extrair algo semelhante do cinema, certamente foi um dos mais bem-sucedidos nesse esforço.

Se o cinema de Tarantino possui algo que a Arte Pop também manifestou, tal conexão reside naquilo que a escola possui de mais poderoso: sua relação com objetos banais. São quinquilharias que, 
mais uma vez, retornam diante de nós: agora, porém, como uma estranha assombração. Algumas vanguardas flertaram com essa liberação de forças fora de nosso controle, e a mais conhecida experiência com tal "cicatriz do espírito", como disse Merquior, esteve na exploração dos sonhos pelo surrealismo. Era uma tentativa de lidar com tudo que parecia difícil de aceitar conscientemente, permitindo que, através da pintura, não se precisasse aguardar pela noite para que ela revelasse aquilo que o dia não suportava. Mas a Arte Pop ia em outra direção.

Olhar para um suposto inconsciente parece desnecessário quando algo ainda mais fantástico se encontra na própria sociedade de consumo e em sua infinidade de bugigangas. A Arte Pop oferecia acesso a esse mundo tão recorrente; e, também, tão difícil de lidar. A força do estilo esteve na problematização que impôs à estética. Através de uma experiência voltada para o mundo externo, suas obras nos concediam a oportunidade de retirar a ingenuidade que tais manifestações continham. Observa-se não os desejos invisíveis vindos das profundezas do próprio eu, mas um esteticismo vazio e brutal, cuja presença não se pode evitar. Se a obra de Tarantino mantém sempre um caráter tenso, escatológico, que usualmente reside em seu uso da violência, isso se deve a tal diálogo.

Seus filmes guardam um tom pouco palatável, como a brutalidade que pode despertar a qualquer momento. Não soa estranho que Harvey Weinstein tenha tentado convencê-lo a retirar de Cães de Aluguel (Reservoir Dogs, 1992) a cena da orelha, como Biskind (2004) nos narra. Se a qualquer momento um caráter intragável põe seus filmes no limite do aceitável, isso se deve ao fato de lidarem com a violência como um atributo unicamente plástico, uma forma que se manipula como bem se entende. Seu trabalho depende desse grafismo impróprio, uma reação roubada do filme de horror de baixo orçamento; mas que, em seu caso, ganha sentido devido a uma extensa reflexão sobre o caráter da representação.

Claro, há limites para o quão longe se pode ir, como em toda ideia radical numa máquina de dimensões como as do cinema, Tarantino se depara com muitas contradições. Algumas vezes, parece que ele se retrai frente ao quão longe ainda poderia ir. Parece sensato afirmar que, nessa inconcretude de formas tão precisas, seu cinema talvez tenha tão somente aberto uma porta ainda não totalmente explorada. Nosso diretor é um crítico perspicaz, mas seu trabalho parece permeado por uma escassa reflexão sobre aquilo que ele próprio alcançou em termos dos questionamentos introduzidos por essa sua técnica. Ou, talvez, falte apenas um Truffaut a entrevistá-lo com a devida atenção, como o cineasta francês fez com Hitchcock. 


\section{ALCEU}

ISSN: 2175-7402

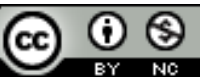

Mas voltemos à análise. Pois as imagens elaboradas por Tarantino não são apenas as de violência plástica. Suas melhores invenções estão em seus personagens, estes pelos quais ele mantém tanto carinho. Alguns problemas sempre interessaram imensamente a esse diretor. O principal talvez seja a lealdade. Em seu trabalho, vínculos são sempre importantes, e não causa espanto que o afeto várias vezes exploda em vingança. Pois o ódio cego sempre espreita quando algo precioso se rompe. Em Kill Bill (2003, 2004), ninguém poderia imaginar outro desfecho para o personagem de David Carradine, pois Beatrix Kiddo (Uma Thurman) jamais desistiria de sua revanche. Porém, de todos os elos, os mais importantes parecem ser os vínculos entre homens.

Essa conexão desperta em Tarantino um fascínio muito pontual. Tal ideia está presente nos oponentes secretos de Cães de Aluguel, pois aquilo que um dia ligou o Sr. White, ou Larry (Harvey Keitel), e o Sr. Orange, ou Freddy (Tim Roth), desfez-se no instante que o ex-comparsa revelou sua identidade de policial. Há uma imensa camaradagem entre Rick Dalton (Leonardo DiCaprio) e Cliff Booth (Brad Pitt), mas ambos se distanciam bastante de outros personagens criados pelo diretor. O próprio filme interpreta essa dupla pela metade, pois não se compreendem muito bem tais criaturas caso se acredite que se resumem a alguém que é "mais que um irmão, menos que uma esposa".

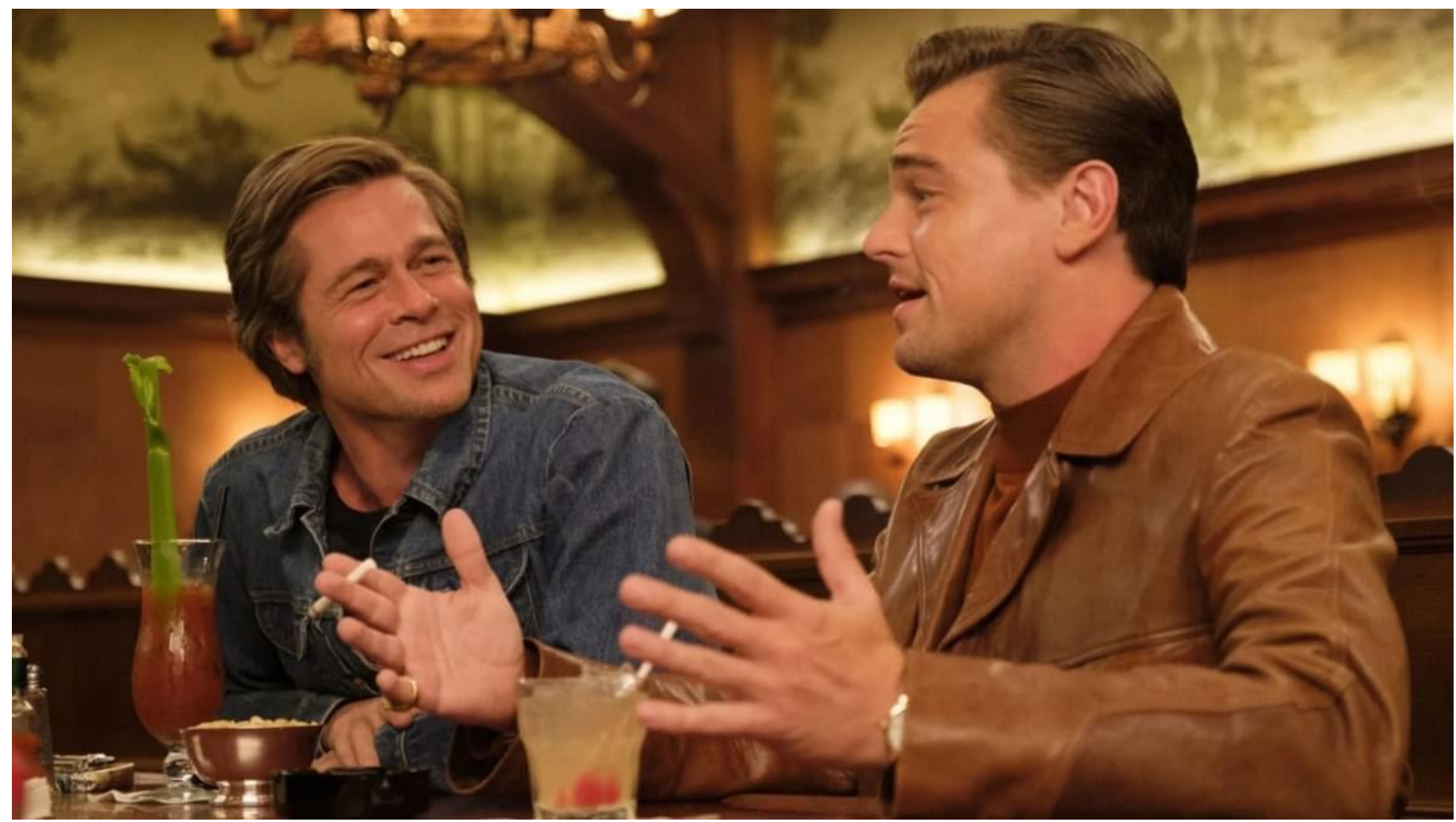


Uma chave está numa das melhores interpretações sobre Cães, contida no belo estudo de Edward Gallafent (2005). Para ele, o filme versa sobre o exército de soldados sempre leais, numa conexão endógena que os protege da insanidade do mundo do crime. Decerto, essa tropa é parte de um universo de caos e violência; mas, dentro das muralhas que ocupam, há uma certa ordem, desde que nada viole tal conexão. É para isso que se cria uma hierarquia bastante rígida, sempre tensa. Esse embate estava já na abertura do filme: na rixa entre o Sr. Blonde, ou Vic Vega (Michael Madsen), e o Sr. White, antecipando aquilo que se radicaliza após todos se virem trancados no galpão; ou na disciplina que Joe Cabot (Lawrence Tierney) impõe quando o Sr. Pink (Steve Buscemi) nega a gorjeta.

Contudo não há gangue alguma em Era uma vez. Numa crítica notável, A.O. Scott (2019) nos apontou para a relação cavalheiresca entre Rick e Cliff, como um vínculo típico àquele mundo de cortesãos que Hollywood parece um dia ter sido. Embora já tenha refletido sobre o afeto em muitas ocasiões, Tarantino nunca havia pensado dessa perspectiva sobre o elo entre dois homens. Pois ambos tomam parte nessa sociedade na qual todos os esforços se voltam pela busca por um lugar ao sol, esse desejo por afirmação para os quais os filmes - o esforço de criá-los e, através deles, mostrar-se ao mundo - se tornam apenas um bom pretexto. Em Los Angeles, os indivíduos lutam por respeito dentro dessa sociedade cujas posições parecem quase inexpugnáveis (DIDION, 1979).

De lá, todos esperam alguma coisa; e Rick está imerso em sua fração desse jogo. Se a gangue não está mais no centro, o cenário se desloca para outro território: a vida doméstica dos personagens. Pois as casas sempre ocuparam um lugar importante em Tarantino. Eram parte decisiva de Pulp Fiction (1994), com seus espaços domésticos que correspondiam a um universo protegido de outro tipo: agora, um mundo onde casais diversos levavam suas vidas. Havia o lar de Marsellus (Ving Rhames) e Mia (Uma Thurman), frio como costumam ser as residências dos milionários cinematográficos; a de Jimmie (Quentin Tarantino) e Bonnie, estranhamente suburbana frente às atividades ilegais ali em curso; dos traficantes Lance (Eric Stoltz) e Jody (Rosanna Arquette), onde tudo é analógico e suburbano: a balança, os piercings artesanais, o leite com cereal e a televisão.

Não é casual que, agora, Tarantino ofereça tanta importância às casas de Rick e Cliff. Elas são uma de suas imagens estilizadas, para as quais o restante do filme serve como pretexto. Há quase que um convite para bisbilhotarmos nesses dois lares. $\mathrm{O}$ ator vive na histórica Cielo Drive; seu dublê, num trailer atrás de um drive-in. São moradas bem diferentes. Esta última nos é apresentada apenas uma vez, numa 


\section{ALCEU}

ISSN: $2175-7402$

cena aparentemente sem qualquer importância. Tarantino gosta desses episódios em que nos distrai com um aparente despropósito, quando, na verdade, muito nos vai ser então revelado. Pois, em meio a uma conversa banal, o "Quarteirão com Queijo" de Pulp Fiction nos ensinou o quão longe iam os negócios de Marsellus, informação indispensável para entender que Butch Coolidge (Bruce Willis) não possuía lugar para se esconder.

Em Era um Vez, precisamos dessa cena para apreendermos a sagacidade que permitirá a Brandy, o cachorro de Cliff, concretizar a vingança que todos ansiavam contra a Família Manson. Mas não se trata apenas disso. A sequência singela na qual o dublê adestra o cachorro com seu jantar nos oferece um desses muitos momentos familiares. Estão ali o cão e sua carne, e nosso herói com seu macarrão instantâneo - juntos, homem e animal forjam um lar, numa imagem tão estranha quanto inocente. Mais interessante se torna o fato de Cliff ter substituído a esposa por esse cachorro, conclusão óbvia quando se analisa seu passado - um tanto terrível - que o filme faz questão de narrar.

No conjunto da obra de Tarantino, o único equivalente a tal momento, em sua estranheza e em sua cotidianidade, talvez seja a sequência em que Bill prepara um sanduíche para B.B. (Perla Haney-Jardine) pouco antes do confronto final com Beatrix. Em 2019, são as pizzas e margaritas que desdobram essas outras imagens já usadas outrora. O lar é um espaço valioso. Ao invadir esse universo de amizade, companheirismo e afeto, os integrantes da Família Manson não poderiam terminar de outro modo - caso já não parecesse indispensável puni-los por tantas outras barbaridades.

Mas o elo entre Rick e Cliff vai além dessa amizade. Está na ligação que mantêm um como o duplo do outro. Que Tarantino tenha escolhido essa imagem do dublê se deve menos à citação a Burt Reynolds e Hal Needham ou a Steve McQueen e Bud Ekins, e mais a um compromisso com sua própria estética. Pois há duplos de vários tipos em Era uma vez. Afinal, todo ator tem sempre algo dessa dualidade, emprestando a si próprio para outrem. E, no cinema, essa sensação se torna ainda mais intensa graças à imagem projetada na tela. No filme de 2019, ninguém menos que dois atores definem a história: não apenas Rick, mas também Sharon Tate (Margot Robbie). Um homem, seu substituto e uma mulher surgem como três criaturas que se alternam, cujas trocas de posição constroem um sistema.

Mesmo quem não entendeu nada sobre esse filme percebeu a relação tensa com fatos concretos, absolutamente enviesados. O mesmo já havia ocorrido com Bastardos inglórios (Inglourious Basterds, 


\section{ALCEU}

ISSN: $2175-7402$

2009), no qual Tarantino decidiu matar Hitler, proporcionando essa realização a si mesmo. Dez anos depois, algo semelhante ocorre. Para explorar essa ideia, o diretor escolheu por Tate. Que se trate de uma imagem se mostra decisivo: afinal, essa atriz serve apenas como pano de fundo para seu projeto. No universo paralelo de Era uma vez, os papéis de destaque são invenções, para os quais a realidade surge como cenário. Talvez por isso Tarantino tenha decidido ignorar na coletiva de imprensa de Cannes a questão sobre a escassa importância dessa personagem feminina.

Squeaky - ou Lynette Fromme (Dakota Fanning) - é bem real, mas a sua participação na trama é lateral. São igualmente concretos Tex Watson (Austin Butler); Sexy Sadie, ou Susan Atkins (Mikey Madison); e Katie, ou Patricia Krenwinkel (Madisen Beaty). De tão pequeno, o papel de Charles Manson (Damon Herriman) talvez até passasse despercebido. Mas Pussycat (Margaret Qualley), criação de Tarantino, recebe uma importância que nenhuma dessas figuras ocupa. Para o diretor, os fatos se mostram úteis ou não, um instrumento para a fantasia se desenrolar. São um playground no qual transcorre um jogo incoerente. Se Tate existe no filme, é apenas como contraponto à ideia de um ator e seu duplo.

Em Era uma vez, essa fabulação com o sósia está em todo lugar. Rick havia sido um caçador de recompensas, mas apenas na televisão. Na pele de Jake Cahill, esteve pronto a valer a justiça no território sem lei do Oeste. Os filmes de Tarantino estiveram povoados de pistoleiros, mas, aqui, ele optou por atores encenando um papel. Os embates de Rick eram apenas filmagens semanais no Rancho Spahn. E é exatamente lá que seu dublê de outrora vai parar quase por acaso, antes de a Família Manson se tornar verdadeiramente perigosa. Na tensão intrínseca à cena, Tarantino não perde a oportunidade para exercitar o ofício de criar esses seus ícones.

Pois a postura do dublê nessa sequência surge como um resumo brilhante de toda a ética do faroeste. Cliff age como um nobre, encarnando um exemplo paradigmático do herói - algumas vezes imperfeito, mas, ainda assim, um herói. Quando se nega a aproveitar-se de Pussycat, age, decerto, por medo da lei. Mas, ao mesmo tempo, move-se pelo código de conduta que o torna quem é. Contudo tal ética mostra-se ainda mais clara na sua relação com o velho George (Bruce Dern). Como um homem determinado a colocar ordem no Oeste, Cliff insiste, até o limite da própria segurança, em escutar da boca do cego que está bem, que aqueles que cumprem o papel de selvagens não abusaram dele de maneira alguma. 
Há tensão nessa sequência, mas sua conclusão terá ainda de esperar pelo desfecho do filme. Contudo não se trata de um passatempo na trama: o momento é essencial no jogo de imagens estilizadas. Os vilões reais que vivem no antigo cenário de um programa cancelado - assassinos concretos num mundo de fantasia - ainda não estão prontos para o clímax. Se, num ponto, a violência ainda espera por ocorrer, num outro extremo a ação se desdobra através de uma luta de outro tipo. Atores passam por heróis enquanto os dublês se preparam para as façanhas que cabem aos homens de coragem. Pois, enquanto Cliff se vê às voltas com esses inimigos concretos, Rick se digladia com os conflitos da fantasia. De um a outro, há dois extremos dessa coleção de imagens: um deles encena a luta que, quase sempre, é o segundo quem conduz.

Não é despropositado que o Rancho Spahn se alterne com o cenário de Lancer (1968-1970), mais uma série de televisão entre a realidade e a imaginação. Lá, onde as falas podem ser refeitas de um modo impossível na vida, Rick encena mais um vilão. Com seu bigode e casaco hippie, o physique du rôle de seu personagem nem é tão diferente do próprio Manson. O mesmo ocorre com seus atos, sequestrando crianças e ameaçando-as de morte, pois DeCoteau equivale agora aos vilões que retornam no final de Era uma vez. Como complemento, Tate parece ideal. Nesses duplos que Tarantino tanto se esforça por criar, nada seria mais preciso que investigar as duas atrizes: Robbie e a própria Sharon, que, por um único instante, será um personagem representado por ela própria.

Numa das sequências de Era uma vez, vemos Tate numa matinê de Arma secreta contra Matt Helm (The Wrecking Crew, 1968, de Phil Karlson). Na luta de Hollywood, a sessão Ihe confirma a posição que ocupa. Contudo há mais que disso. Pois, não por descuido, quando a personagem de Robbie vê a si mesma em cena, os espectadores de Era uma vez assistem a Freya na pele da própria Sharon, enquanto a Tate de Tarantino se encontra também ao alcance de nossos olhos. A cena guarda uma das composições mais instigantes que o diretor já construiu sobre a distância e a proximidade entre esses ícones. Na ausência de compromisso do filme, importam apenas imagens: da atriz; da atriz que encarna outra atriz; da atriz que atua dentro do filme projetado naquele que vemos. 


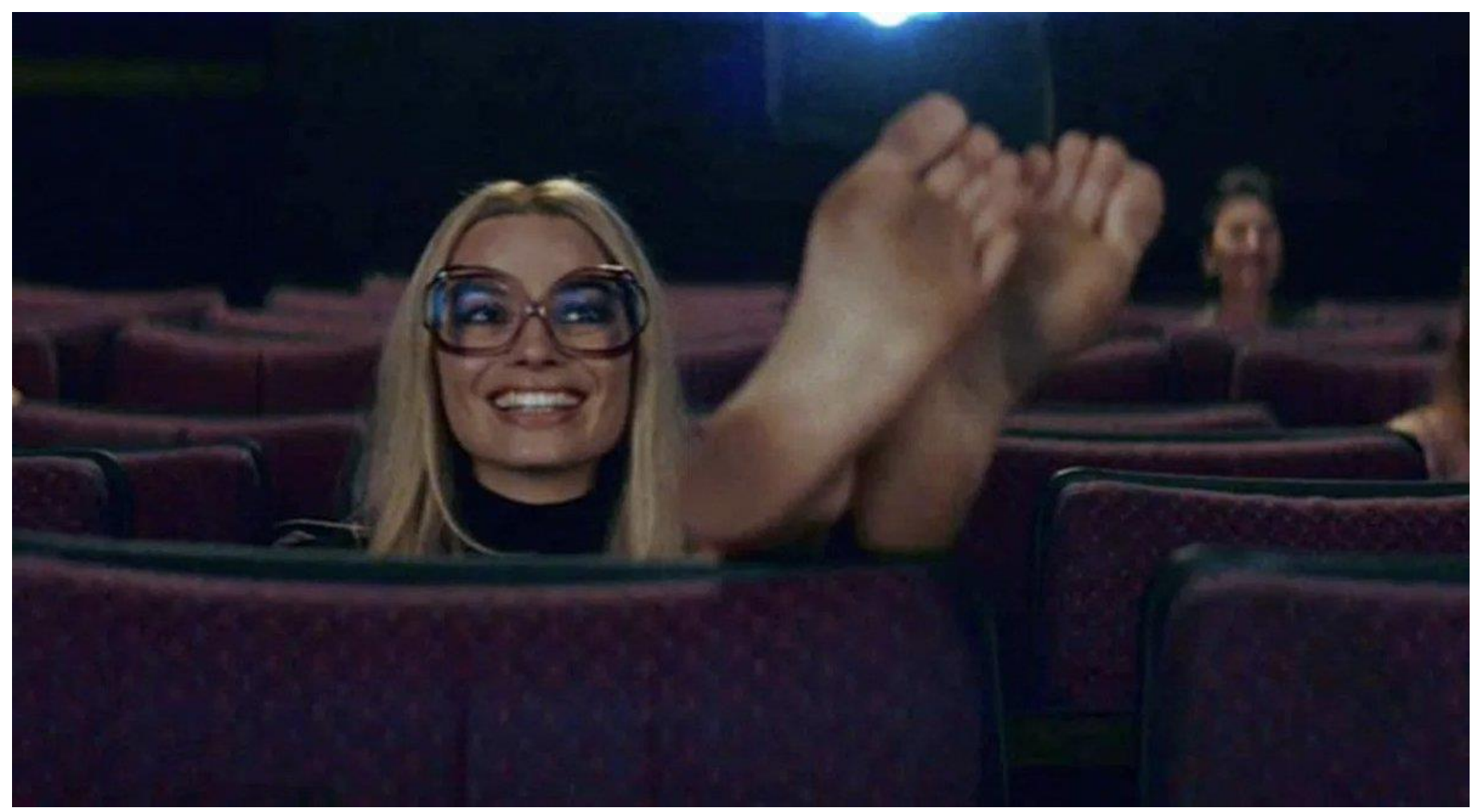

Voltemos à narrativa. Tate, em franca ascensão, está enfeitiçada pelo seu próprio brilho. Enquanto isso, Rick se vê em queda livre, interpretando bandidos no mesmo instante em que seu dublê se apresenta como o herói que ele próprio encenou um dia. Porém a narrativa não basta. 0 jogo de espelhos se torna muito mais importante. Todo o enredo está aí para mostrar algo além dele próprio. Pois o sósia especialista na ação condensa a expressividade retida no âmago desse tipo de cinema: os gestos promissórios de um homem nem tanto para outro homem, mas para uma imagem. O cinema não existe sem um ator no lugar de alguém - contudo, quando os prédios explodem e os carros dão piruetas, tudo fica a cargo de um duplo no lugar daquele que já cedeu a si próprio. A ideia já apareceu no Stuntman Mike (Kurt Russell) de À prova de morte (Death Proof, 2007), contracenando com a dublê de Uma Thurman em Kill Bill, Zoë Bell, no papel dela mesma.

Tudo isso conduz, no clímax, a uma história real francamente distorcida. A infidelidade serve à fantasia de Tarantino, que dá à verdade o destino que melhor lhe convém. Enfim, o diretor realiza seu desejo - e também o nosso - de salvar Tate da Família Manson, como já havia feito com a Segunda Guerra de Bastardos. Sua solução inclui o mesmo lança-chamas que Rick havia empunhado em The 14 Fists of McCluskey. É o único instante em que esse ator ultrapassa seu duplo. Por apenas um momento, a mise-enscène independe de Cliff, do mesmo modo que ocorreu no set de Paul Wendkos, que, no mundo de 
Tarantino, dirigiu Dalton. Se Era uma vez fez questão de mostrar o incômodo do ator com a arma no cenário fictício, era somente como uma prova de que, agora, não é o duplo quem entrará em cena para salvar o dia.

Há um momento de redenção nesse instante, como nos outros dois filmes de Tarantino que, com Era uma vez, compõem uma trilogia informal de reabilitação da história. Como Anthony Lane e Richard Brody (2019) perceberam, quando o diretor tenta rever os registros factuais, o fogo surge recorrentemente como um instrumento purificador. Tal imagem apareceu não apenas em Bastardos, mas também em Django livre (Django Unchained, 2012), quando a revanche contra a Casa-Grande que a põe abaixo ocorre por meio de chamas. Nada disso existe como um signo cujo sentido se deveria analisar. Opera apenas como parte de um sistema de imagens colhidas alhures, e é através delas que o filme se constrói.

Tudo na obra de Tarantino é deliberadamente falso. Nosso artista é um mestre do deslocamento, combinando e revendo as frações da engrenagem mais anódina e sem graça da indústria cultural: os seriados de televisão dos anos 50 e 60, dos quais retirou Ty Hardin a fim de compor Rick (HAMPTON, 2019). Na repetição monótona do mesmo, soa difícil encontrar um concorrente tão à altura das tiras de quadrinho de Roy Lichtenstein quanto a participação de Dalton num seriado como Bronco (1958-1962), por exemplo. É um material pouco importante, mas Era uma vez o trata como um repertório exemplar, tornando-o disponível para que possa ressurgir no mais pleno deslocamento.

Aqui, como sempre ocorre na obra de Tarantino, tudo se encontra fora de lugar, pois todas as imagens se misturaram. Por um lado, Bastardos pôde falar sobre a Segunda Guerra apresentando a solução mágica de Comandos que agiam como a resistência Apache. Django aplicava a concepção de Tarantino sobre o faroeste-espaguete, versando sobre o fascismo ao nos mostrar um mundo no qual a vida nada vale, mas a morte tem um bom preço. Quando Era uma vez termina, estão todos bem: Rick, Sharon e também Hardin. Nada escapa a esse imenso afeto que Tarantino tem com suas imagens. Mas sua obra se sustenta não apenas devido a esse sentimento.

Esse gigantesco carinho produz conexões cuja relevância se estende para além das razões pontuais que conduziriam a tal sensação. Os filmes de Tarantino se sustentam devido à flexibilidade com que o diretor manipula registros sensíveis. Suas imagens surgem como objetos "já-prontos", instrumentos para 
os quais a narrativa comparece como um gesto a colocá-los em movimento. Sem dúvida, Tarantino é um dos grandes roteiristas do cinema, e suas tramas possuem um sabor mais do mais delicioso. Mas suas obras se alimentam de algo bem maior. Outros bons roteiristas já imitaram seus enredos e o resultado foi pífio. Pois nada ocorre sem a reconciliação dos objetos, concedendo-os nova vida, e, talvez, também a essa arte.

\section{Conclusão}

Qual a natureza do cinema de Tarantino? Sua obra bem poderia ser acusada de kitsch, como uma estetização vazia de certos elementos supostamente complexos. Mas não se trata disso. Ao contrário, seu trabalho indica a concretização de princípios da estética que, em vez de negar a industrialização da cultura, buscam uma alternativa para lidar com ela. O objetivo de tomar para si imagens de circulação internacional não pode ocorrer sem uma intensa ironia. O que se enxerga não possui a expectativa de representar o que quer que seja. Esse ato garante a distância necessária, bem distante da apropriação automática de um conjunto de fórmulas. Para isso, a especificidade de seu trabalho se define pelo uso de ruínas do cinema, concedendo-lhes uma dimensão tão particular.

Sua produção se torna possível num contexto em que essa necessidade de conviver com imagens alcança uma recorrência intensa a ponto de tornar as representações parte do cotidiano. A saturação do mundo com certo tipo de cultura industrializada bem poderia se restringir à repetição infinita do mesmo, em prol de algumas categorias exauridas de sentido. Mas atos estéticos como aqueles contidos na Arte Pop e no cinema de Tarantino manipularam essas formas, revirando-as. Pois elas retiram sua força da saturação. Essa postura se encontra inscrita num movimento estético que buscou reconciliar a representação; mas, curiosamente, se torna relevante também para um cinema que, aparentemente despretensioso, termina por condensar problemas fundamentais de nosso tempo.

É assim Tarantino consegue acionar a cinefilia, retirando uma energia em relação a imagens do passado que se encontram contidas na memória. Muitos diretores buscaram meios para lidar com esse passado do cinema. Na obra de Tarantino, a especificidade reside na reordenação desses registros. Em jogo, encontra-se sua capacidade de retomar objetos esquecidos devido à sua recorrente presença, encarando de outro modo itens invisíveis graças à sua ubiquidade. Outros diretores seguiram caminhos 
semelhantes, e as influências do cinema europeu sempre foram marcantes (CARROLL, 1982; PYE; MYLES, 1979). Mas, para esse artista pontual, interessava mais retomar itens que recebem um novo valor devido a características que deveriam empobrecê-los. Nisso reside a sua riqueza.

João Martins Ladeira

ORCID: https://orcid.org/0000-0002-7381-6380 Universidade Federal do Paraná, Programa de Pós-graduação em Comunicação, Curitiba (PR), Brasil. Doutor em Sociologia pelo IUPERJ E-mail: joaomartinsladeira@gmail.com

Recebido em: 14 de setembro de 2020.

Aprovado em: 22 de novembro de 2021.

\section{Referências:}

ARENDT, Hannah. Introduction: Walter Benjamin: 1892-1940. In: BENJAMIN, WALTER. Illuminations: Essays and Reflections. Nova York: Schocken Books, 1968. p. 1-55.

BENJAMIN, Walter. A obra de arte na época da possibilidade de sua reprodução técnica. Estética e sociologia da arte. Belo Horizonte: Autêntica, 2017. p. 7-48.

BENJAMIN, Walter. Ensaios reunidos: escritos sobre Goethe. São Paulo: Duas Cidades, 2009.

BENJAMIN, Walter. Origem do drama trágico alemão. São Paulo: Autêntica editora, 2013.

BUCK-MORSS, Susan. Dialéctica de la mirada: Walter benjamin y el proyecto de los pasajes. Madrid: MIT Press, 2001.

BRUNETTE, Peter. Interview with Quentin Tarantino. In: PEARY, GERALD. Quentin Tarantino: Interviews, Revised and Updated. Jackson: University Press of Mississippi, 2013. p. 23-28.

CARROLL, Noël. The Future of Allusion: Hollywood in the Seventies (And beyond). October, Nova York, v. 20, p. 51-81, 1982.

CIMENT, Michel; NIOGRET, Hubert. Interview with Quentin Tarantino. In: PEARY, GERALD. Quentin Tarantino: Interviews, Revised and Updated. Jackson: University Press of Mississippi, 2013. p. 53-60.

DIDION, Joan. The White Album. Nova York: Simon \& Schuster, 1979. 
FRITH, Simon. Performing Rites. Cambridge, Mass: Harvard University Press, 1998.

GAGNEBIN, Jeanne Marie. História e narração em Walter Benjamin. São Paulo: Perspectiva, 1994.

GALLAFENT, Edward. Quentin Tarantino. Nova York: Pearson Education Limited, 2005.

HALL, Stuart. Da Diáspora. Belo Horizonte: Ed. UFMG, 2003.

HAMPTON, Howard. Slow Death. Film Comment, Nova York, ago. 2019, p. 30-31.

LANE, Anthony; BRODY, Richard. Surface Tension. New Yorker, Nova York, 8 maio 2019, p. 76-77.

LIPPARD, Lucy. A Arte Pop. São Paulo: Verbo Edusp, 1976.

MERQUIOR, José Guilherme. Arte e sociedade em Marcuse, Adorno e Benjamin: ensaio crítico sobre a escola neohegeliana de Frankfurt. Rio de Janeiro: Tempo Brasileiro, 1969.

MERQUIOR, José Guilherme. Sentido e problema do "pop" - "pop" e hiperrealismo. Formalismo e Tradição Moderna. São Paulo: É Realizações, 2015. p. 401-422.

PYE, Michael; MYLES, Lynda. The Movie Brats: How the Film Generation Took Over Hollywood. Nova York: Holt, Rinehart and Winston, 1979.

ROUANET, Sérgio Paulo. Apresentação. In: BENJAMIN, WALTER. Origem do Drama Barroco Alemão. São Paulo: Brasiliense, 1984. p. 1-47.

ROUANET, Sergio Paulo. Édipo e o anjo: itinerários freudianos em Walter Benjamin. Rio de Janeiro: Tempo Brasileiro, 1981.

SCOTT, A.O. Buddies Bonding In Tarantino-Wood. New York Times, Nova York, 26 jul. 2019, p. C1(L).

WILLIAMS, Raymond. Culture and Society, 1780-1950. New York: Anchor Books, 1958.

WOLIN, Richard. Walter Benjamin: An Aesthetic of Redemption. Berkeley: University of California Press, 1994.

\section{Resumo}

O artigo interpreta Era uma vez em... Hollywood, de Tarantino, através de uma postura que, inspirada na crítica imanente de Benjamin, discute a estética numa sociedade industrializada, em busca de critérios que permitam sua interpretação. Busca-se indicar de que modo Tarantino se 
concentra em traços de certos gêneros usualmente menosprezados, construindo seu cinema a partir desses restos. O texto aponta problemáticas comuns entre tal gesto e a Arte Pop. Sem indicar qualquer adesão entre o diretor a essa vertente artística, o texto indica que ambas convergem num projeto homólogo, lidando com imagens saturadas, na tentativa de oferecer-Ihes outra dimensão.

Palavras-chave: Arte Pop. Quentin Tarantino. Teoria crítica.

\section{Abstract}

The article interprets Once Upon a Time in ... Hollywood, by Tarantino, through a posture that, inspired by Benjamin's immanent critique, discusses aesthetics in an industrialized society, looking for criteria that allow its interpretation. It seeks to indicate how Tarantino focuses on traits of certain genres usually overlooked, building his cinema from these remains. The text points out common problems between such gesture and Pop Art. Without indicating any adhesion between the director to this artistic aspect, the text indicates that both converge in a homologous project, dealing with saturated images, in an attempt to offer them another dimension.

Keywords: Pop Art. Quentin Tarantino. Critical Theory.

\section{Resumen}

El artículo interpreta Once Upon a Time in ... Hollywood, de Tarantino, a través de una postura que, inspirada en la crítica inmanente de Benjamin, discute la estética en una sociedad industrializada, buscando criterios que permitan su interpretación. Busca indicar cómo Tarantino se enfoca en rasgos de ciertos géneros usualmente pasados por alto, construyendo su cine a partir de estos restos. El texto señala problemas comunes entre tal gesto y Pop Art. Sin indicar ninguna adhesión entre el director a este aspecto artístico, el texto indica que ambos convergen en un proyecto homólogo, que trata con imágenes saturadas, en un intento de ofrecerles otra dimensión.

Palabras clave: Pop Art. Quentin Tarantino. Teoría crítica.

Este artigo é publicado em acesso aberto (Open Access) sob a licença Creative Commons Attribution Non-Commercial (CC-BY-NC 4.0), que permite que outros remixem, adaptem e criem a partir do seu trabalho para fins não comerciais, e embora os novos trabalhos tenham de lhe atribuir o devido crédito e não possam ser usados para fins comerciais, os usuários não têm de licenciar esses trabalhos derivados sob os mesmos termos. 